\title{
Applied aspects of investments in innovation in Bulgarian companies
}

\author{
Dimitar Blagoev ${ }^{1 *}$ \\ ${ }^{1}$ Industrial Business Department, University of National and World Economy, "Osmi dekemvri" str., \\ 1700 Studentski grad, Sofia
}

\begin{abstract}
Investment and innovation have traditionally been seen as interconnected areas of activity. Clarifying this relationship in the business practice of Bulgarian companies is an interesting task, from a scientific and applied point of view. The intensity of innovation resulting from the dynamics of the global economy also implies pressure on companies to make more and more investments in new products, new technologies, new working methods and managements, etc. At the same time, not all innovative technologies and/or products are characterized by the necessary costeffectiveness. This requires companies to apply appropriate methods for assessing the profitability of investments in innovation, as well as methods for assessing the risk of such investments. The purpose of this article is to investigate the practice of Bulgarian companies (based on a limited range of researched but completely randomly distributed) in applying approaches and methods for assessing the effectiveness of investments in innovation. To achieve the main objective, methods such as: literary review, observation, survey, two-dimensional statistical distribution, analysis and synthesis of primary information, comparative analysis, expert evaluation, etc. are used. In conclusion, some summaries of good practices and recommendations for increasing the effectiveness of these processes in the practice of companies are given.
\end{abstract}

\section{Innovation and investment in innovation in companies}

One of the main functions performed by each business organization are investment and innovation functions. Investment and innovation have traditionally been accepted as interconnected areas of activity and there is a specific causal link available to them. The disclosure of this link in the business activities of the Bulgarian companies is an interesting task, from a scientific and applied point of view. The intensity of innovation stemming from the dynamics of a globalizing economy also implies pressure on companies to make more and more investments in new products, new technologies, new working methods and governances, etc. At the same time, not all innovative technologies and/or products are characterized by the necessary cost-effectiveness (despite their high degree of novelty, their coefficient of useful activity does not allow them to derive economic effects). This requires

\footnotetext{
*Corresponding author: blagoev@,unwe.bg
} 
companies to apply appropriate methods for assessing the profitability of investments in innovation, as well as methods for assessing the risk of such investments.

Assessing the effectiveness of investment in innovation is an important element of the overall innovation and investment process, but it must go along with risk assessment in similar types of projects. Risk and rate of return are linked, and increasing one leads to an increase in the other. However, in order to assess the risk in innovation projects, it is necessary to develop them in many variations and when only one of their basic parameters is changed. This is usually done in order to avoid a comprehensive combination of the different options in the use of the theory of combination. Most often, the basic parameters are developed in three variants - optimistic, pessimistic and realistic. Another approach is to determine the realistic value and to do a positive or negative deviation from it.

\section{Innovation and investment projects}

By its very nature, each innovation project is an investment project, as I have no way to develop and implement innovation without incurred certain investment costs. At the same time, not every investment project is innovative or at least not an innovation project in the context of relevance in the concept of innovation.

Management science sees innovation as a process of finding (identifying) some unsolved problems for consumers, companies (business organizations) or society as a whole and offering an affordable solution. In most cases, the search for a solution has focused on productivity (performance) issues, especially as far as business organizations are concerned. According to Kim and Mauborgne [1], successful companies, both oriented and with a vision for the future, should focus on generating and creating "Blue Oceans" innovations (new opportunities through provoking and creating new needs), rather than betting and looking for such innovations and competitive strategies (increased efficiency) in the "red oceans" (which are an element of so-called incremental (improved) innovation).

According to Ivan Georgiev [2], investment projects are a one-time investment of cash in any assets to ensure the receipt of income and/or other positive result over an extended period. He also determines that projects differ in too many signs: scale (large, small); assets (real, financial); (markets, industries, etc.); objectives (minimizing costs, increasing revenues, increasing capacity); (high-risk, low-risk); way of development (with their own strength, from external units) and variantity (complementary, mutually exclusive), etc. [2]

On the other hand, an innovation project revolves around certain criteria (and should include at least one of them) [3]:

- aimed at development of an innovative (new) product or service (product or service innovation);

- employ innovative methods and approaches (process innovation);

- lead to improvement of innovative and learning capabilities of the project executor (organizational innovation);

- be realized in a close interaction with the project owner (user innovation).

\section{Methodological scheme of the study}

For the purposes of the practical study, the method of expert evaluation based on the survey shall be used. The experts surveyed fill in a structured questionnaire with key issues for the observation. The questions are divided into several categories to obtain information to achieve the underlying objective. The questionnaire is structured in the following areas:

- Information about the number of realized innovation and investment projects by the company; 
- Information on the main sources of financing of innovation projects;

- Information on the basic methods used for efficiency assessment and risk assessment when investing in innovations in the company;

- Determination of the effects and results in and after the realization of the innovation projects;

- Commitment to investing in innovation in the company - company funds dedicated to innovation and new developments; staff in the company working on innovative projects, etc.

The analysis is based on two-dimensional distributions of current information and retrospective analysis over the past 5 years [4].

\section{Study results}

The first question aims to find information on how many investment projects the business organisation has implemented in connection with the development and/or implementation of innovations over the past five years. This way we can determine what the activity of business organizations is and what it is influenced by. The companies that implemented between 3 and 5 innovation projects $-47 \%$ had the largest share. Then there are $22 \%$ with fewer than 3 projects. Some respondents ( $15 \%$ of them) indicated that their business organisations had not implemented any such project in the last 5 years (Figure 1 ).

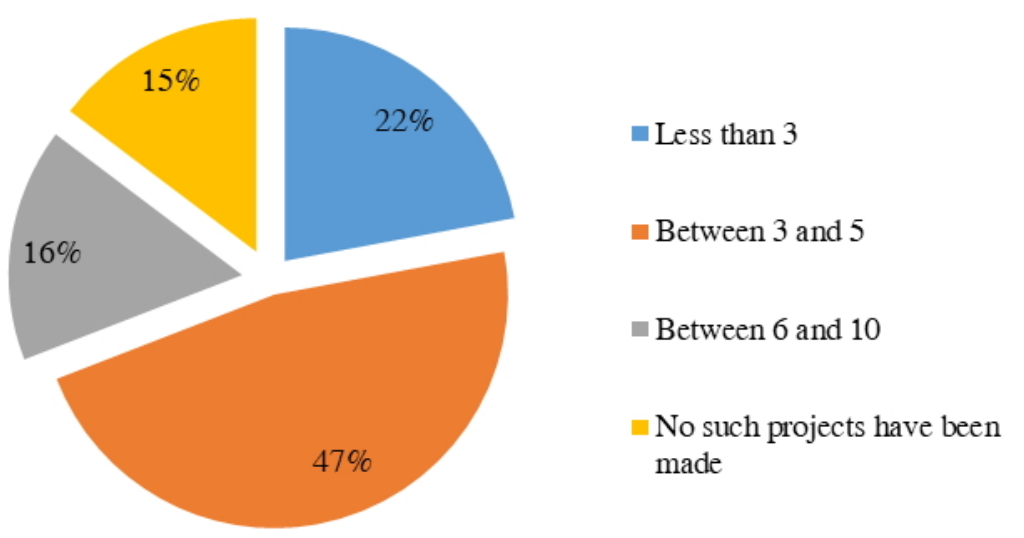

Fig. 1. Number of projects implemented in the last 5 years

The data show relatively low innovation activity of the surveyed respondents. They are randomly selected and include 90 business organizations from different sectors of the economy and with different profile.

Undoubtedly, the innovation activity of business organizations is a high-risk activity, and on the other hand it requires a large volume of invested funds, which at the same time have unclear rate of returns. This fact also determines certain specificities in the selection of sources for financing innovative projects. A general rule is that business organizations use such sources to finance to which they have access. They also seek to spread the risk through funding between the company itself (implementing the innovation project) and its external partners.

The results related to the activities used by the business organization, the main sources of financing of investments in innovation, show that the most used source of funding is the income from the current activity $-27 \%$ of the respondents. Much less used are the 
possibilities for bank loan - 16\%. They have relatively the same values: additional issue of shares or shares $(12 \%)$; retained earnings $(11 \%)$ EU programmes $(11 \%)$. depreciation and amortization (5\%) (Figure 2). Logically, the highest rates are income from current activity and bank loan as the most affordable sources. In the absence of a well-developed financial market, it is also understandable that the small share of the bond issue as a source of financing for investment in innovation is also understandable. At the same time, few companies take advantage of the opportunities (quite limited in Bulgaria) in capital markets and turning them into public companies. In this way, they can indirectly finance their innovation activities by raising capital from the stock exchange and carrying out an IPO. It also makes an impression on the low share (only 7\%) financing of innovation and innovation projects. Leasing as an element of technological transfer is very suitable for financing innovative projects, but practice in the Bulgarian conditions shows that it is mainly used to finance vehicles and transport (or construction) equipment in companies. In much rarer cases it was used as a means of financing acquired technologies, innovative equipment and other innovative products for the company.

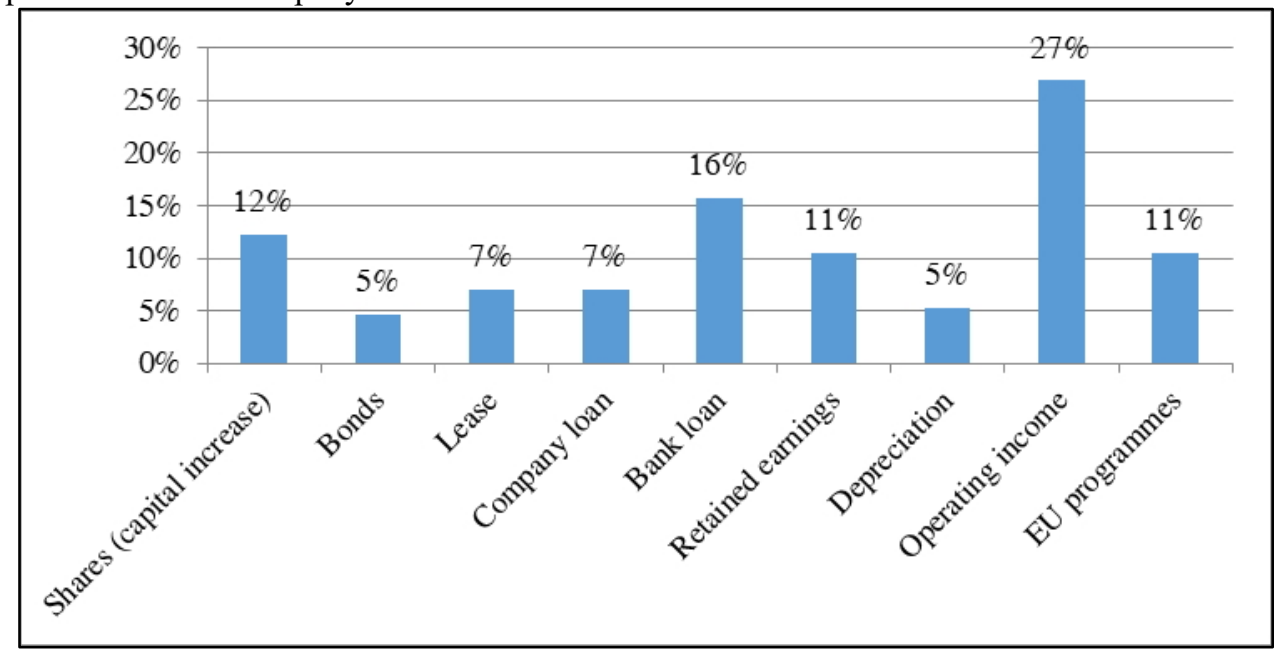

Fig. 2. The main sources of financing used for investment in innovation.

Performance issues are essential for each company and for the projects it implements (whether innovative or not). That's why it's interesting what business organizations apply to evaluate this performance and how often do these things? The theory has defined numerous indicators for assessing the effectiveness of investments and different approaches in determining the effects of similar activities in the company.

The preferred methods (indicators) for assessing the effectiveness of investment innovation projects are distinguished in seven possible directions: net present value (NPV); internal rate of return (IRR); efficiency ratio or profitability index (PI); the term of redemption of the investment; cost/benefit method; net income from the investment; methods are not used but rely on intuition (Figure 3). Relatively close results are obtained by the first 4 methods: profitability ratio $(21 \%)$; cost/benefit methods $(20 \%)$; net present value $(19 \%)$ and internal rate of return $(17 \%)$. The lowest percentage received the answer that such methods were not relied on, but the assessment is made based on intuition (1\%). Respondents' responses showed that a variety of methods were used to obtain an accurate assessment of the project's effectiveness rather than rely on intuition. Another conclusion is that companies rely on traditional and proven methods rather than intuitive methods. This is good practice, i.e., thus, in most cases, reasoned investment decisions are obtained. 


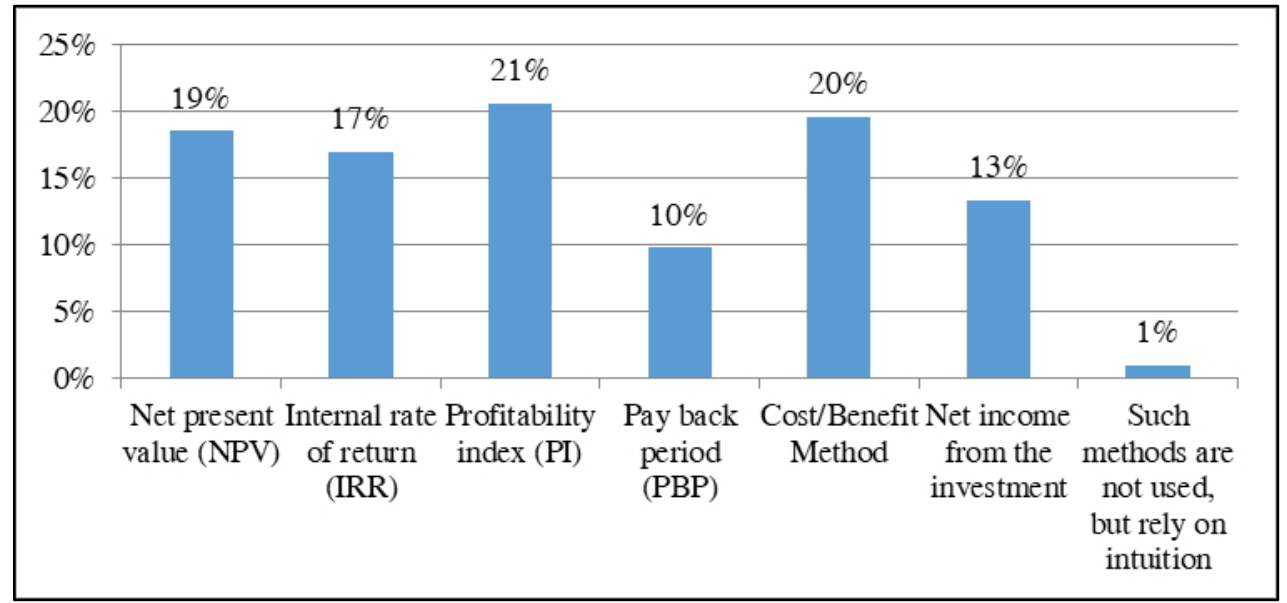

Fig. 3. The basic methods used to assess the effectiveness of investment projects for innovation.

As mentioned, a little above in the article, effectiveness and risk go hand in hand and are in a proportional dependence. Innovation projects characterized by high risk must also be characterized by a high rate of return, which at the same time is very uncertain. It is therefore essential that companies assess the risk in their innovation projects. This is particularly important when we have a lot of variation and a need to compare between effectiveness and risk level across different options.

When were asked which are the preferred, basic methods of risk assessment in innovation projects, respondents highlighted the standard deviation and dispersion $(20.8 \%)$ and critical point of sales or break-even point (BEP) $(20.1 \%)$ as the most preferred methods. Monte Carlo $(4.5 \%)$ and no such methods are used, but intuition is used $(5.8 \%)$ (Figure 4). The results show that respondents prefer to determine the risk in the projects and give preference to accurate methods. On the other hand, very suitable but relatively complex methods such as simulation methods (Monte Carlo) are largely logically less preferred.

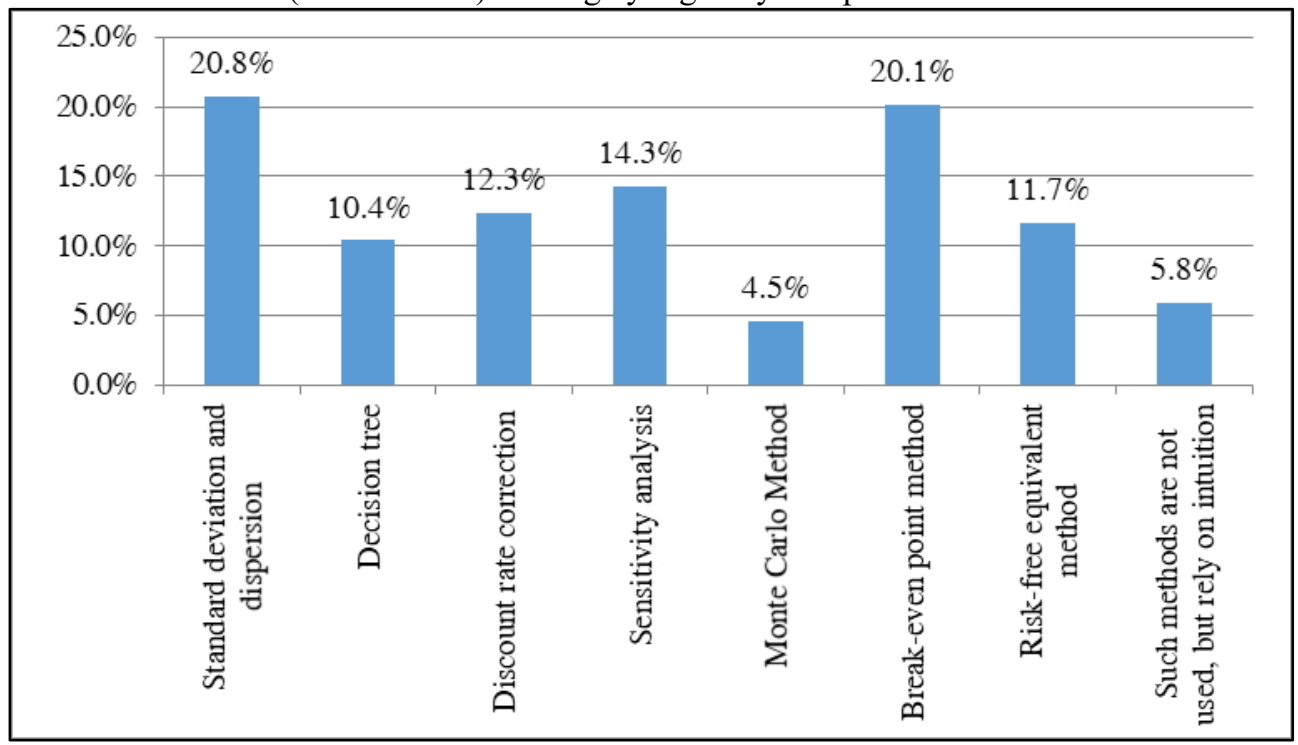

Fig. 4. Basic risk assessment methods used in innovation projects. 
Assessing the effectiveness and overall effect of developed and/or implemented innovations are two different things. For this, in addition to a purely financial point of view, the effectiveness of innovation also affects the overall activity of the company. The synergy effect they produce is essential for the company's growth.

When were asked (Figure 5) how they would determine the results of investing in innovation in the business organisation, $51.5 \%$ of respondents replied that they were satisfied but there was something to improve. More than $1 / 4$ of the respondents $(27.9 \%)$ are satisfied with the results and $17.6 \%$ are very satisfied. It can be noted that the final answers, we are not satisfied and extremely satisfied, receive extremely low values $-1.5 \%$. These results show that in general a large number of business organizations in Bulgaria are happy with investing in innovation, but most of them take into account the fact that there is something to improve in their work and to a significant extent.

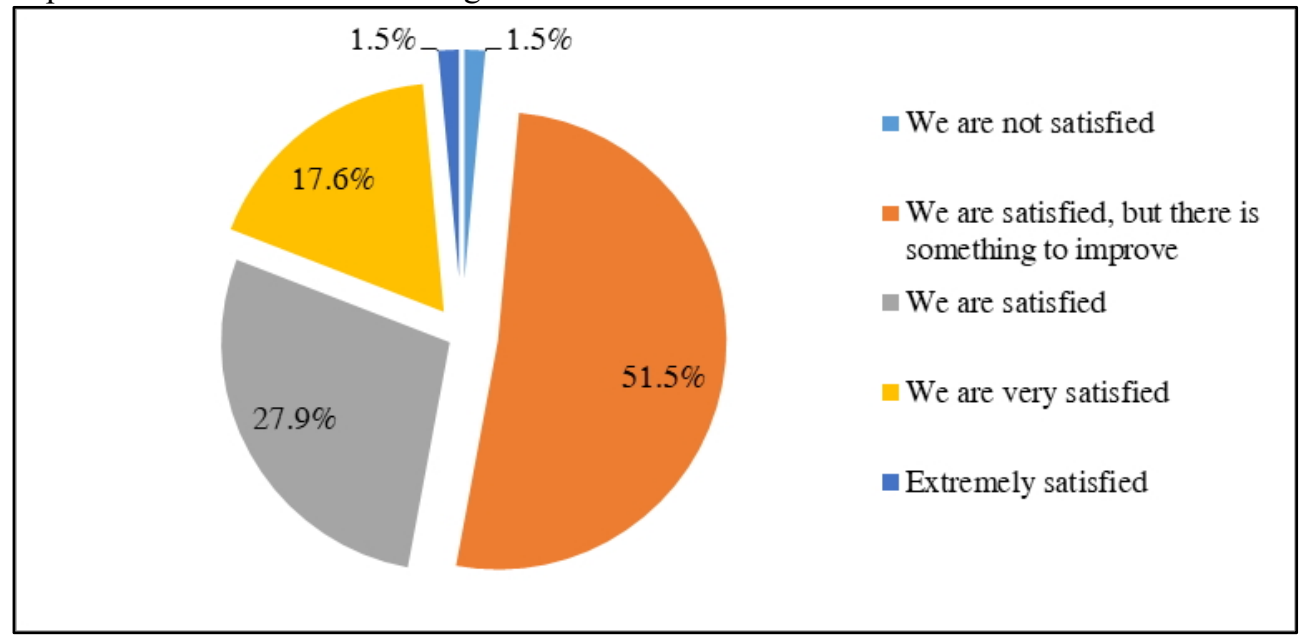

Fig. 5. Results of investing in innovation in the business organization

In addition to the level of satisfaction (or frustration), there are various effects that can be sought from the realization of innovations in the business organization. Such effects can be: increased jobs; increased exports and internationalization of the business organization's activities; substitution of imported raw materials, materials and products and corresponding reduction of imports; replacement of recycled materials and products; use of recycled materials and recyclability of the product; energy efficiency and energy-saving technologies. The first two of these effects received the highest share of responses- $22.9 \%$ and $21.8 \%$ respectively (Figure 6). The other effects receive relatively close shares, with the exception of a decrease in imports. This result can be explained by the increasing globalization of the economy and the opportunities for Bulgarian business organizations to participate in it. 


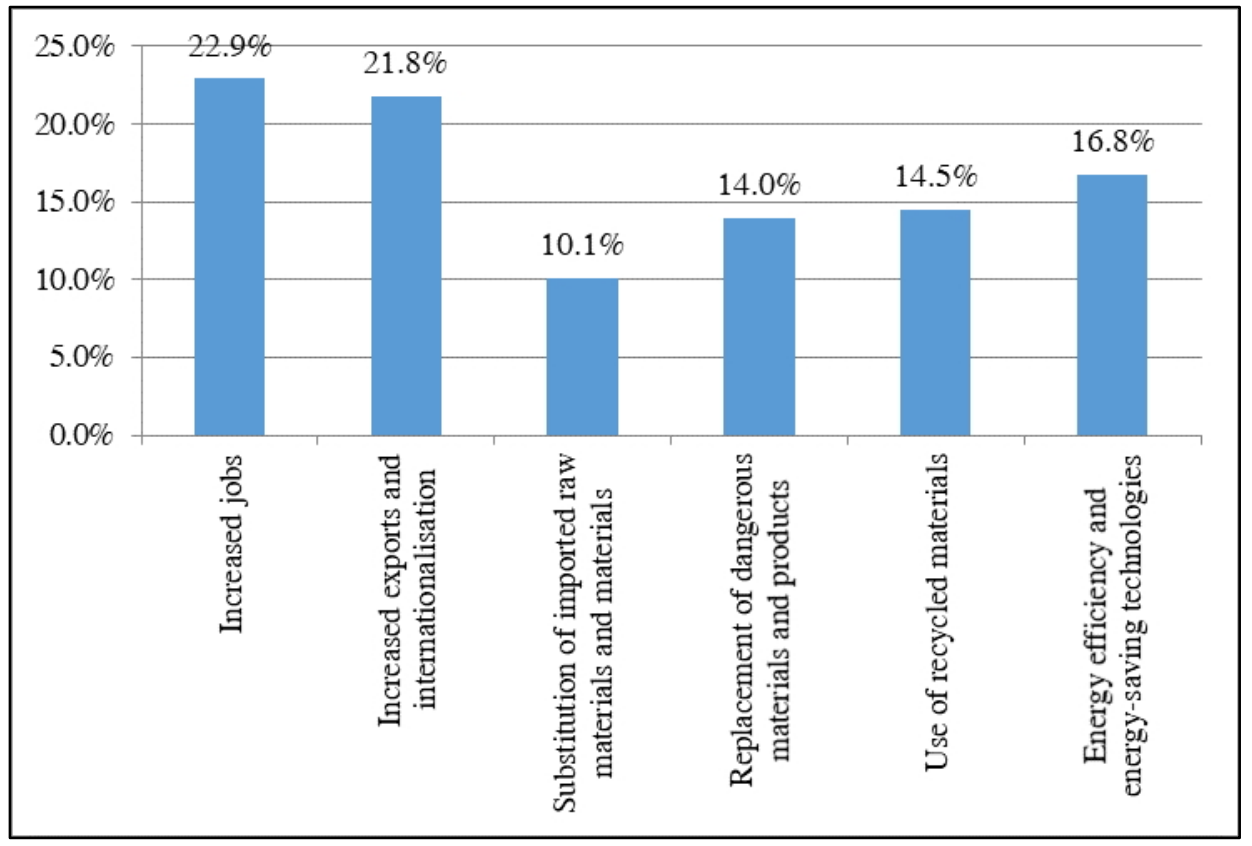

Fig. 6. Effects of implementation of innovation projects in the business organization.

On the other hand, respondents' responses show that they are concentrating and looking for effects from the innovations developed or implemented primarily in order to ensure the growth of the company through them, rather than to increase the efficiency of the processes.

An important factor in ensuring the efficiency of innovation in the company at both the level of an individual innovation project and at the level of the general effect for the company's activity is the adoption of the innovation ideology and innovation concept by as many of the company's employees as possible. This can only be done by involving more people in innovation processes for the development and implementation of innovations. Here, the design principle of work is very suitable and often used by companies.

Business organisations should strive to involve as many of their staff as possible in the innovation process as well as from different levels of the management hierarchy. The survey shows (Figure 7 ) that in $42.6 \%$ of respondents between $5 \%$ and $15 \%$ of the company's total staff is involved in the innovation process. The percentages of the next two responses are much lower - between $15 \%$ and $30 \%$ of the staff (23.5\% of respondents) and up to $5 \%$ of the staff $(22.1 \%$ of respondents). Over $30 \%$ of the staff participated in the innovation process, only in $11.8 \%$ of the business organizations surveyed. The results show that, in general, a small number of business organizations are involved in the innovation process. 


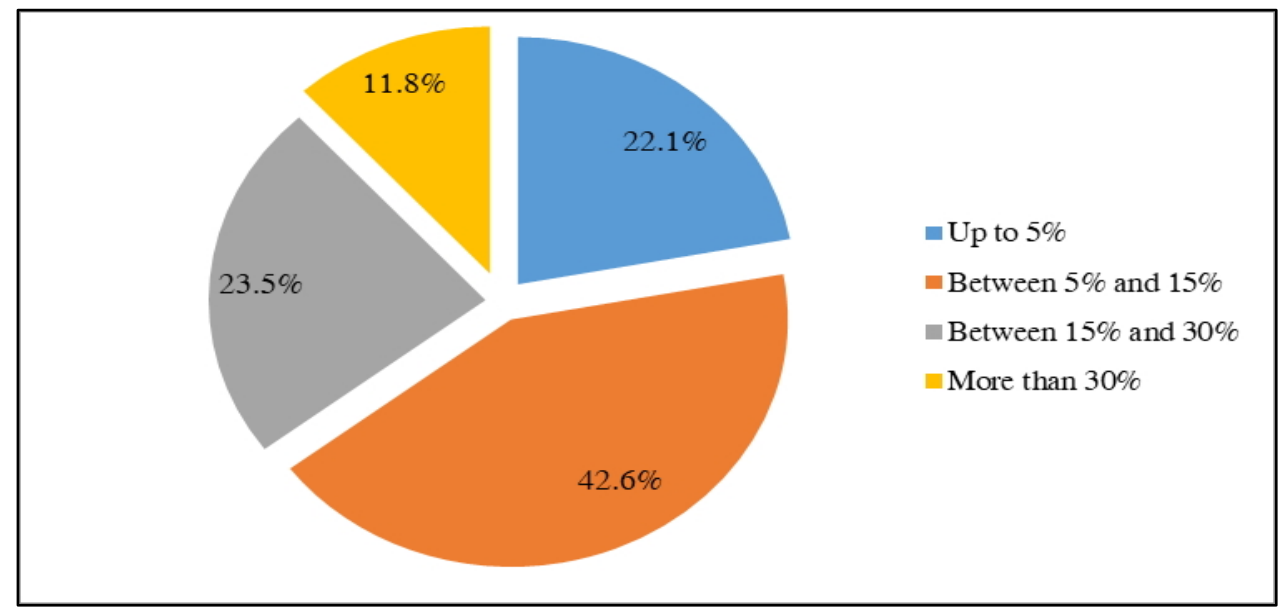

Fig. 7. Share of the staff of the business organization involved in the innovation process

Another important indicator of the dynamics of the innovation process in business organizations is "percentage of $R \& D$ funds allocated from the total revenues of the business organization". This indicator shows us the extent to which the company is willing to risk its own funds for initiating and implementing high-risk investments in innovation projects (Figure 8 ). The majority of respondents $(32.4 \%$ of them) devote between $5 \%$ and $15 \%$ of their R\&D revenues or up to $5 \%(30.9 \%$ of them). That is, $63.3 \%$ of the business organizations participating in the survey devote up to $15 \%$ of their R\&D revenues. It should also be noted the majority of respondents who do not carry out such activity $-13.2 \%$.

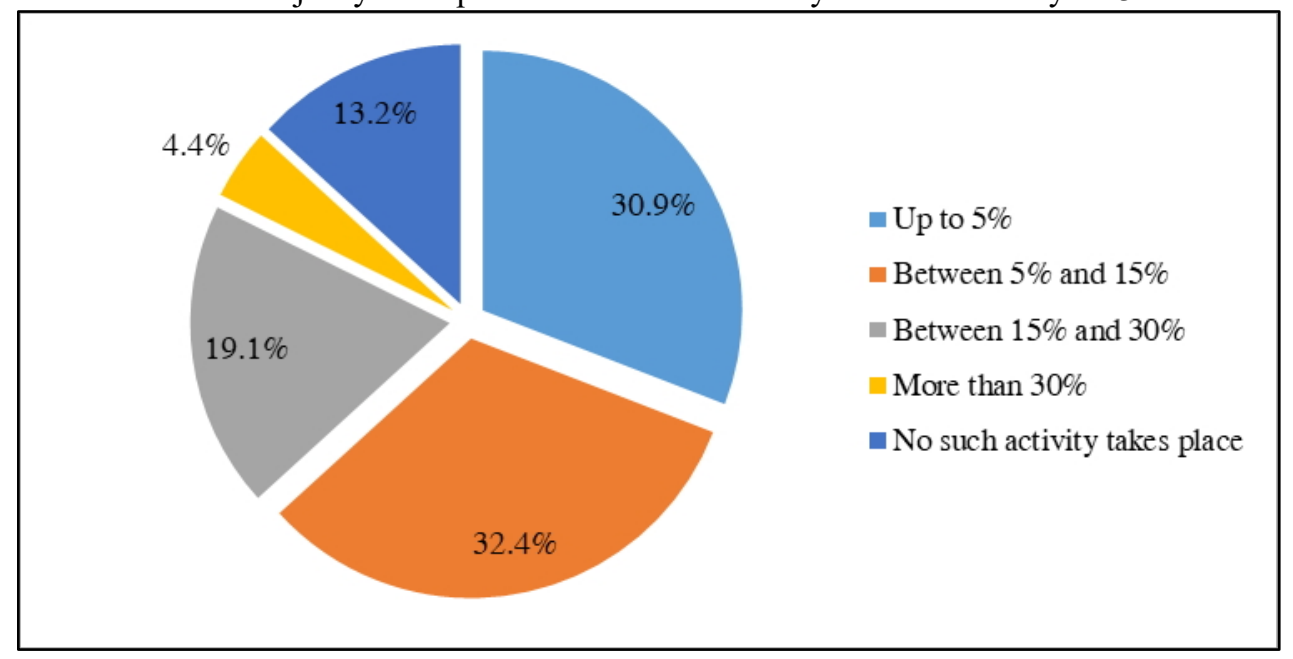

Fig. 8. R\&D funds as $\%$ of the total revenue of the business organization.

In countries with limited innovation capabilities (such as Bulgaria, which is defined in the category of modest innovator according to the European Union Scoreboard ranking) the methods and forms of technological transfer are an appropriate tool for ensuring innovation at company level. Therefore, technology transfer is a basic method for Bulgarian business organizations to acquire new technologies in different forms: patent rights, licensing, knowhow agreements, etc. (Figure 9). An important indicator is the percentage of funds allocated to transfer technologies from the company's total revenues. Respondents point to higher percentages relative to R\&D funds as \% of revenues: between $5 \%$ and $15 \%-47.1 \%$ of 
respondents and between $15 \%$ and $30 \%-30.9 \%$ of them. This shows that technology transfer is widely used by business organizations.

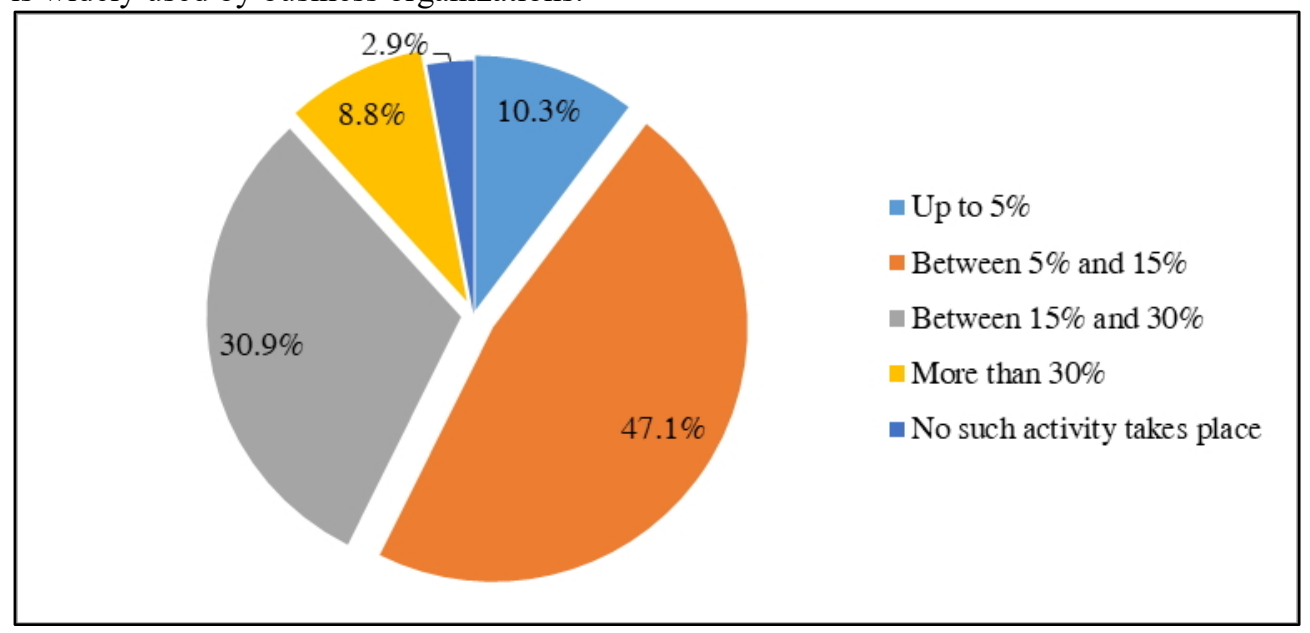

Fig. 9. Innovation costs (implemented through technology transfer) as \% of the company's total revenues

\section{Summaries and conclusion}

The findings reported above, in the analysis, show a very unfavorable trend, which is also confirmed by the research carried out at a common European and global level in terms of the degree of innovation of national economies. The Bulgarian economy and its building companies are still (although not the small period of its operation in a recognized market economy) is a modest innovator, with a relatively small share of innovative companies in the country (about 20-25\%).

An interesting fact is also the assessment and self-assessment of the companies themselves in terms of innovation and innovation activities. Many of them point out that they set aside funds for R\&D, carry out similar activities, develop innovative projects and participate in innovation networks at home and abroad. And while this is understandable in the international companies surveyed, which have representations in the country, i.e. as the activities in the field of innovation in them is rather a product of the implementation of innovative policies, strategies and plans developed at corporate level (parent company, headquarters, etc.), then the views on the innovation activities of local business organizations hardly correspond to our last place in the rankings of degree of innovation and innovative competitiveness at European and global level.

\section{References}

1. W. Chan Kim, R. Mauborgne, Blue Ocean Strategy, (Harvard Business School Press, Ed. Helicon, 2014)

2. Iv. Georgiev, Osnovi na investiraneto, (Publishing Complex UNWE, Sofia, 2013)

3. A. Keegan, J.R. Turner, Long Range Plan., 35(4), 367-388 (2002)

4. D. Blagoev, R. Boyadzhiev, Z. Yordanova, Kr.Petkov, Study on the importance of innovative companies for ensuring growth of the national economy, (Publishing Complex UNWE, Sofia, 2021) 